\title{
Is there a role for balloon sinuplasty in treating chronic rhinosinusitis: a teritary centre's experiences
}

\author{
Benjamin Silver, Huw Jones, Mark Ferguson, Prem Randhawa and Peter Andrews \\ Royal National Throat Nose and Ear Hospital, UCLH NHS Foundation Trust, London
}

\section{INTRODUCTION}

Chronic rhinosinusitis is a common problem, the prevalence in Europe has been estimated to be $11 \%{ }^{1}$

The use of Balloon sinuplasty has increased in recent years. ${ }^{2}$ One of the main attractions of the devices is their easy of use through the ergonomic designs and the ability to use them in an office setting under local anaesthetic (LA). ${ }^{3}$ Balloon dilation of the maxillary, frontal, and sphenoid sinuses to treat CRS was first introduced in 2006 and has been shown to be safe and effective. ${ }^{4}$ Over 39,000 ambulatory sinus surgeries are performed per year in the United States. ${ }^{4}$

NICE estimated a potential $£ 7.4$ million per year saving for NHS England by 2020 if balloon sinuplasty was adopted in preference to traditional Endoscopic Sinus Surgery (ESS). ${ }^{5}$ This recommendation was based on comparing ESS to balloon sinuplasty performed under LA in a clinic setting. 6,7

\section{METHODOLOGY}

Prospective study of all patients who underwent balloon sinuplasty. All patients had pre-operative skin prick testing for common aeroallergens and CT sinuses graded according to the Lund-Mackay scoring system.

Additionally all patients had the following pre \& post operatively:

- Visual analogue scores for facial pain, rhinorrhoea and nasal obstruction

- Peak nasal inspiratory flow volumes (NIPF)

- SNOT-23 questionnaire

\section{INCLUSION CRITERIA}

- Aged between 18 - 80 years old

- Complaint of facial pain, nasal obstruction, rhinorrhoea or post nasal drip with symptom duration $>3$ months

- CT sinus, Lund Mackay Score $<10$

- No previous ESS

\section{AIM}

To evaluate the efficacy of balloon sinuplasty in the treatment of CRS.

\section{RESULTS}

Nasal obstruction was significantly improved by balloon sinuplasty intervention (Table 1 ). $42 \%$ of patients $(5 / 12)$ had their procedure under LA. In this cohort of patients the surgical aims were fully realised and there were no complications. Anecdotally, all patients reported reduced need of use of CRS medications post operatively.

\section{CONCLUSIONS}

- Despite the small sample size, we show there is statistically significant reduction in nasal obstruction and subjective improvements in all other parameters measured.

- Balloon sinuplasty is both therapeutically and cost effective. Performed under LA it is ideally suited to the clinic setting.

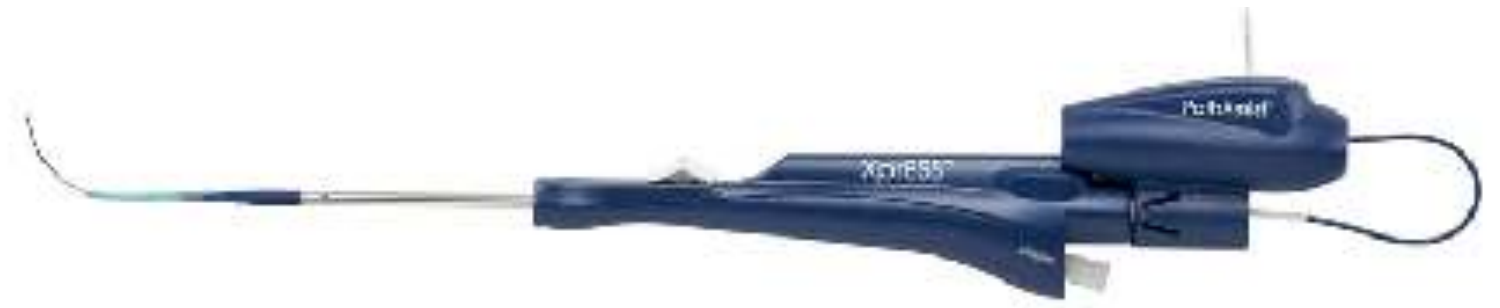

\begin{tabular}{|c|c|c|c|}
\hline Table 1 - Results & $\begin{array}{c}\text { Pre } \\
\text { procedure }\end{array}$ & $\begin{array}{c}\text { Post } \\
\text { procedure }\end{array}$ & t test \\
\hline Nasal obstruction & mean 6.5 (range 5 -10) & mean 4.6 (range 0 - 10) & $\begin{array}{c}3.26>2.15 \\
\text { Significant difference }(p< \\
0.05)\end{array}$ \\
\hline Rhinorrhoea & mean 5.6 (range 1 - 10) & mean 4 (range 0 - 10) & $\begin{array}{c}0.29<2.15 \\
\text { No significant difference }\end{array}$ \\
\hline Facial Pain & mean 5.6 (range 0 - 10) & mean 4.7 (range 0 - 10) & $\begin{array}{c}0.42<2.15 \\
\text { No significant difference }\end{array}$ \\
\hline SNOT-23 & mean 52.11 (SD 9) & mean 43.83 (SD 6) & $\begin{array}{c}0.68<2.16 \\
\text { No significant difference }\end{array}$ \\
\hline NIPF & mean 95.63 (SD 53.0) & mean 118.57 (SD 49.9) & $\begin{array}{c}0.9117<2.16 \\
\text { No significant difference }\end{array}$ \\
\hline
\end{tabular}

1. Hastan D et al. Chronic rhinosinusitis in Europe - an underestimated disease. A GA 2LEN study. Allergy 66:1216-1223, 2011. 2.Schiller JS, Lucas JW, and Peregoy JA. Summary health statistics forU.S. adults: National Health Interview Survey, 2011. National Center for Health Statistics. Vital Health Stat. 10:1-207, 2012

3.Cutler $\mathrm{J}$ et al. Standalone balloon dilation versus sinus surgery for chronic rhinosinusitis: A prospective, multicenter, randomized, Am J Rhinol Allergy 27, 416-422, 2013

4.Svider PF et al. Evolving trends in sinus surgery: What is the impact of balloon sinus dilation? Laryngoscope 128(6), 1299-1303, 2018 5. https://www.nice.org.uk/guidance/mtg30 (accessed 19/06/2018)

6. Gould J, Alexander I, Tomkin DO and Brodner MD. In-office, multisinus balloon dilatation: 1-Year outcomes from a prospective,

multicenter, open label trial. Am J Rhinol Allergy 28, 1-8, 2014

7.Levine S, Truitt T, Schwartz M, Atkins J. In-office stand-alone balloon dilation of maxillary sinus ostia ethmoid infundibula in adults with chronic or recurrent acute rhinosinusitis: A prospective, multi-institutional study with 1-year follow-up. Ann Otol Rhinol Laryngol 122(11): 665-671, 2013.
Copyright $\odot 2017$ Benjamin Silver, Huw Jones, Mark Ferguson Prem Randhawa and Peter Andrews Correspondance to peterandrews@nhs.net 